\title{
TEKNIK CETAK FOTO CHLOROPHYLL PRINT
}

\author{
Cyrilus Uky Basuki \\ Program Studi Penciptaan Fotografi, Program Pascasarjana ISI Yogyakarta \\ Jln. Suryodiningratan No. 8, Yogyakarta \\ No.HP.0817228112,E-mail:mail4uq@gmail.com
}

\begin{abstract}
ABSTRAK
Sejarah mengatakan Thomas Wedgewood memulai kegiatan merekam objek pada sebuah media dua dimensi semenjak tahun 1800-an. Kegiatan merekam ini terus berulang hingga perkembangannya memengaruhi banyak aspek dalam dunia fotografi. Teknologi fotografi era digital memang menawarkan kemudahan dan kenyamanan penggunanya. Proses cetak fotografi pada era digital memungkinkan sebuah foto dicetak di banyak ragam material, seperti kaca, kain, dan kayu. Artinya teknik cetak cukup mengundang daya tarik karena memiliki nilai-nilai visual, seperti bentuk, kontras, dan tekstur. Seniman fotografi berusaha mewujudkan imaji penciptaan karya seninya melalui pertimbangan ide kreatif dan pencapaian estetis. Penggabungan teknikal dengan memanfaatkan pengolahan komputer dan pengolahan analog saat ini cukup diidolakan untuk menampilkan ciri khas seorang fotografer, seperti teknik chlorophyll print yang mengandalkan daun serta proses penyinaran untuk pembentukan image dari proses fotosintesis.
\end{abstract}

Kata kunci: alternative print, chlorophyll print, fotografi, fotosintesis

\section{ABSTRACT}

Photo Print Technique the Chlorophyll Print. In 1800 Thomas Wedgwood began to capture the object on a two dimensional media with photographic materials. This repetitive activity affects many aspects of photography. As in the era of digital photography offers many facilities, convenience, and comfort for the user. Photo printing process in the digital age allows a photograph printed in a wide variety of materials, such as glass, fabric, and wood. It means printing technique is quite inviting appeal because it has a visual values, such as shape, contrast and texture. Many photographic artists try to create an image by considering the creation of creative ideas and aesthetics. Utilizing computer processing and analog processing is the idea of chlorophyll printing technique to form an image by photosynthesis process.

Keywords: alternative print, chlorophyll prints, photography, photosynthesis

\section{PENDAHULUAN}

Teknik cetak dengan menggunakan media daun biasa disebut dengan teknik chlorophyll print yang telah dikembangkan sejak tahun 1990-an. Teknik cetak dengan menggunakan media daun merupakan perkembangan dari teknik cetak anthotype dan fotogram. Pada tahun 1990 seniman yang secara intens mengekplorasi teknik cetak ini adalah Heather Ackroyd \& Dan Horvey. Mereka berdua melakukan riset teknik chlorophyll print hingga sepuluh tahun lamanya. Kedua seniman tersebut memanfaatkan rumput sebagai media cetak foto. Tekniknya mirip dengan cetak foto hitam putih, rumput tersebut dimasukkan ke dalam kamar gelap yang kemudian disinari dengan cahaya ultraviolet dari proyektor yang telah dilapisi film. Layaknya penyinaran lampu enlarger untuk cetak foto hitam putih di atas kertas peka cahaya. Pada media rumput 
penyinaran dilakukan untuk memudarkan pigmen klorofil, yang lama kelamaan berubah warna menjadi kuning dan membentuk dimensi gelap terang. Perbedaan gelap terang warna itulah yang akhirnya membentuk image foto di atas media cetak tersebut (Worobiec \& Spence, 2003:122).

Tahun 2006 Binh Danh menyederhanakan teknik chlorophyll print. Ia merangkai koleksi foto dokumenter dari majalah Life untuk dicetak di atas daun. Binh Danh mengandalkan daun dengan proses fotosintesis untuk pembentukan image. Proses fotosintesis yang berarti "foto" cahaya dan "synthesis" penggabungan, suatu proses biokimia pembentukan zat makanan seperti karbohidrat yang dilakukan oleh tumbuhan, terutama tumbuhan yang mengandung zat hijau daun atau klorofil. Proses fotosintesis sangat tergantung dengan sinar matahari. Proses penyinaran dilakukan secara langsung ke permukaan daun dengan menggunakan film positif. Bagian film yang terang menjadikan warna daun lebih terang, sedang bagian film yang gelap melindungi pigmen daun dan menjadikan warna daun lebih gelap.

Teknik cetak foto dengan menggunakan media daun masih jarang digunakan di Indonesia. Proses teknik cetak dengan menggunakan media daun ini merupakan perpaduan era digital dan era analog dalam fotografi, yang dianggap mampu merangsang memori akan sejarah dan perkembangan fotografi, karena terdapat sebuah pengalaman estetis untuk mencipta sebuah karya fotografi.

\section{METODE}

Proses kreatif menjadi syarat utama dalam mencipta karya seni fotografi. Proses eksplorasi dan eksperimen merupakan syarat mutlak untuk menggunakan teknik cetak chlorophyll print sebagai ide penciptaan. Chlorophyll print merupakan teknik cetak organik, cuaca dan bahan-bahan yang tepat menjadi faktor penting dalam perwujudan penciptaan ini. Teknik chlorophyll print memanfaatkan proses fotosintesis, mutlak sinar matahari dibutuhkan untuk perwujudan image di atas daun. Pengerjaannya dilakukan di pagi sampai dengan sore hari tergantung dengan kondisi cuaca.

Dalam proses perwujudan karya fotografi ini ada beberapa metode yang harus dipersiapkan, seperti peralatan yang digunakan pra dan pasca mencetak. Dalam proses produksi karya ini material yang digunakan adalah sebagai berikut.

\section{Persiapan Alat dan Bahan}

a. Koleksi foto

Foto genre dokumentasi atau bisa genre foto lain.

b. Mesin scanner

Mesin scanner digunakan sebagai alat bantu mereproduksi koleksi foto dokumentasi yang sudah ada.

c. Seperangkat $P C$ dengan software Adobe Photoshop

Seperangkat PC dengan software Adobe Photoshop ini digunakan untuk memproduksi film negatif, sekaligus pengolahan foto.

d. Film positif

Film positif yang nantinya menjadi master pencetakan foto dengan proses fotosintesis.

e. Daun segar

Daun segar merupakan media pencetakan, yang dimanfaatkan zat chlorophyllnya untuk menimbulkan suatu image. 
f. Storage

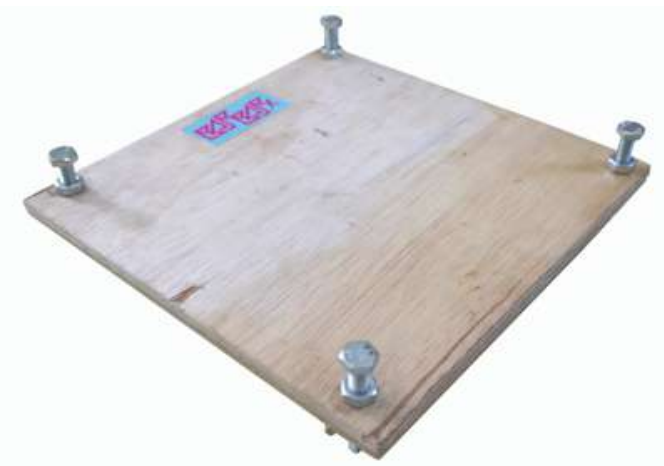

Gambar 1

Storage digunakan sebagai tempat daun setelah proses pencetakan. Sifatnya kedap cahaya, dan udara yang membantu keawetan image, dan menghindari jamur agar daun tidak cepat membusuk. Media penyimpanan ini prinsipnya seperti buku tebal, dimana daun ditekan di dalam halaman buku.

g. Multiplex

Multiplex digunakan sebagai tatakan, tujuannya menahan bentuk daun dan film agar tetap datar tidak terlipat saat proses exposure.

\section{h. Penjepit kertas}

Setelah tatakan, daun, film, dan mika akrilik tersusun penjepit kertas diletakkan di sisisisinya untuk menahan geseran film dan daun.

i. Mika Akrilik Transparan

Mika akrilik dipilih yang sifatnya transparan digunakan sebagai layer untuk menahan film dan daun, selain itu memudahkan sinar matahari menyinari bidang daun untuk berproses fotosintesis.

\section{Komputer Grafis}

Metode cholorophyll print hampir sama dengan fotografi pada era analog, yaitu fotografer menggunakan film untuk mencetak. Penggunaan teknologi komputer dalam teknik chlorophyll print dilakukan untuk menciptakan film positif.

Pengolahan estetik dimulai dari pemilihan foto dokumentasi yang akan dicetak di atas daun. Proses editing dilakukan sebelum melakukan teknik cetak chlorophyll print. Penggunaan fitur-fitur leveling, brightnesscontrast, grayscale mengubah warna menjadi monochrome, dan cropping untuk mengatur komposisi. Foto direproduksi dengan mesin scanner yang dijadikan file JPEG untuk kemudian dijadikan film positif menggunakan bantuan software Adobe Photoshop dan mesin print. File JPEG kemudian diolah menggunakan software Photoshop dengan mengubah warna menjadi monochrome. File JPEG yang sudah menjadi monochrome ini kemudian di-print menjadi film positif, sebagai master film cetak di atas daun. Ukuran film juga sangat menentukan terciptanya image di atas daun. Ukuran film minimal dibuat sesuai dengan ukuran daun, contohnya daun jeruk memilik panjang $22 \mathrm{~cm}$ dan lebar $8 \mathrm{~cm}$ maka ukuran film dibuat sama.

\section{Pemilihan Material Daun}

Beberapa macam daun dari beberapa jenis varian tumbuhan, contohnya daun manga (Mangifera indica), daun jambu (Psidium guajava), daun jeruk (Citrus maxima) pada tanaman buah, dan sri rejeki (Aglaonema crispum), talas (Colocasia esculenta), pisang hias (Calathea lutea), dan enceng gondok (Eichhronia crassipes) pada tanamah hias.

Ada tiga kriteria daun yang digunakan sebagai perwujudan karya chlorophyll print. Yang pertama adalah bentuk daun, yang kedua adalah permukaan daun, dan ketiga adalah susunan tulang daun. Bentuk daun untuk menekankan kesatuan estetis daun dengan image. Pemilihan permukaan daun untuk kemudahan memvisualkan image ke permukaan daun, sedangkan berdasarkan susunan tulang daun karena pertimbangan besar kecilnya media cetak foto. 
Berdasarkan bentuk daun:

a. Elliptical

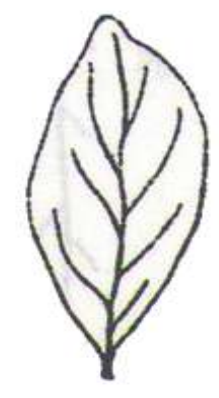

ELLIPTICAL

Gambar 2

Bentuk daun

http://ghinaghufrona.blogspot.com/2011/08/morfologidaun.html

(Diakses pada 26/05/2015-20:00)

b. Orbicular

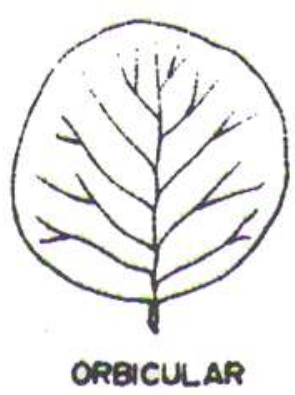

Gambar 3

Bentuk daun

http://ghinaghufrona.blogspot.com/2011/08/morfologidaun.html

(Diakses pada 26/05/2015-20:00)

c. Obovate

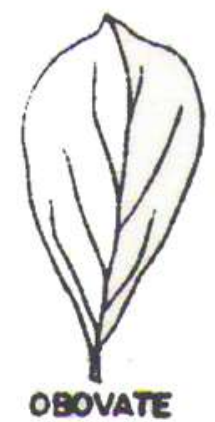

Gambar 4

Bentuk daun

http://ghinaghufrona.blogspot.com/2011/08/morfologidaun.html

(Diakses pada 26/05/2015-20:00) d. Oval

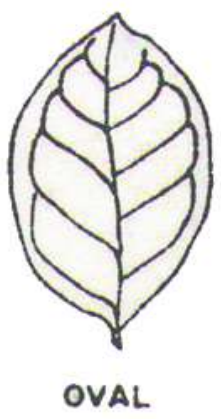

Gambar 5

Bentuk daun

http://ghinaghufrona.blogspot.com/2011/08/morfologidaun.html

(Diakses pada 26/05/2015-20:00)

e. Pinnate

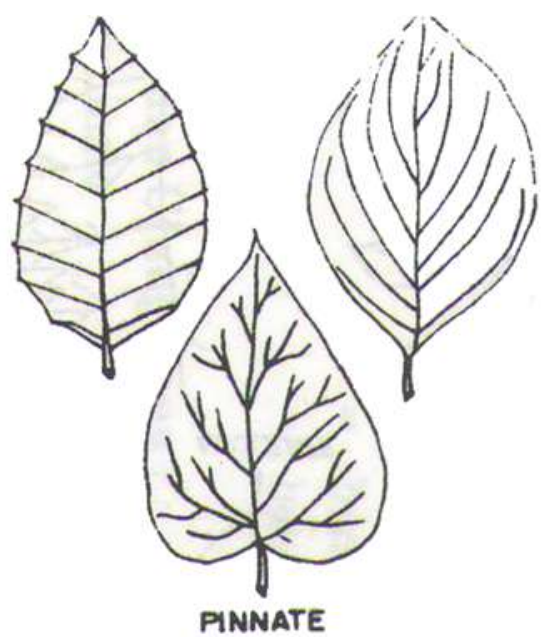

Gambar 6

Bentuk daun

http:/ghinaghufrona.blogspot.com/2011/08/morfologidaun.html

(Diakses pada 26/05/2015-20:00)

\section{f. Remform}

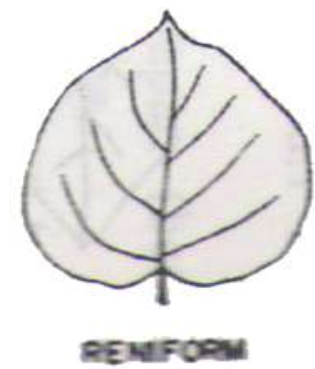

Gambar 7

Bentuk daun

http://ghinaghufrona.blogspot.com/2011/08/morfologidaun.html

(Diakses pada 26/05/2015-20:00) 
Berdasarkan permukaan daun:

a. Licin (Laevis)

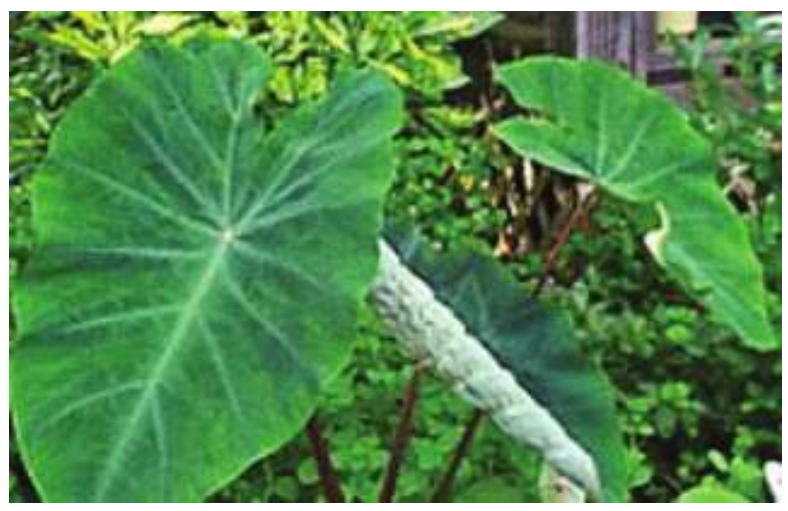

Gambar 8

Permukaan daun

http://mortumklasifikasitumbuhan.blogspot. com/2013/10/bangun-daun_7436.html

(Diakses pada 26/05/2015-20:00)

\section{b. Mengkilat (Nitidus)}

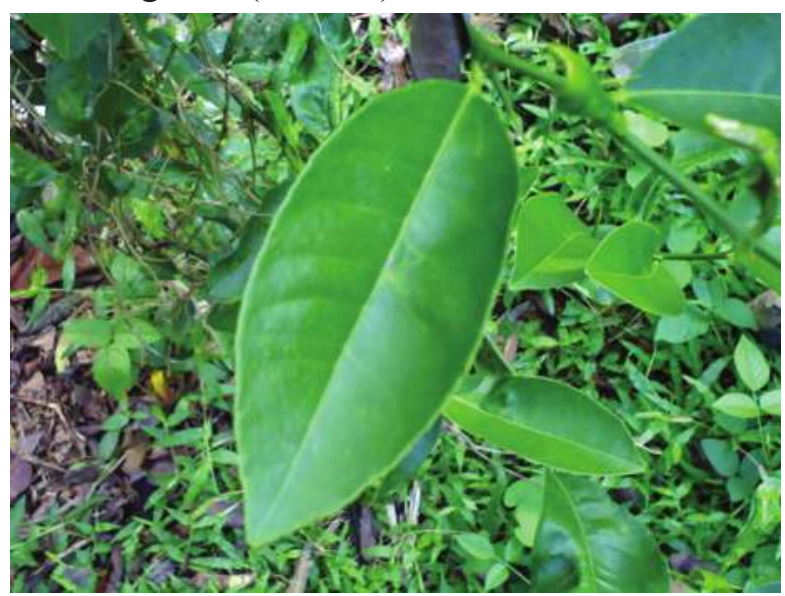

Gambar 9

Permukaan daun

http://andiibm.blogspot.com/2014/04/jeruk-nipiscitrusaurantifolia.html

(Diakses pada 26/05/2015-20:00) c. Berselaput lilin (Pruinosus)

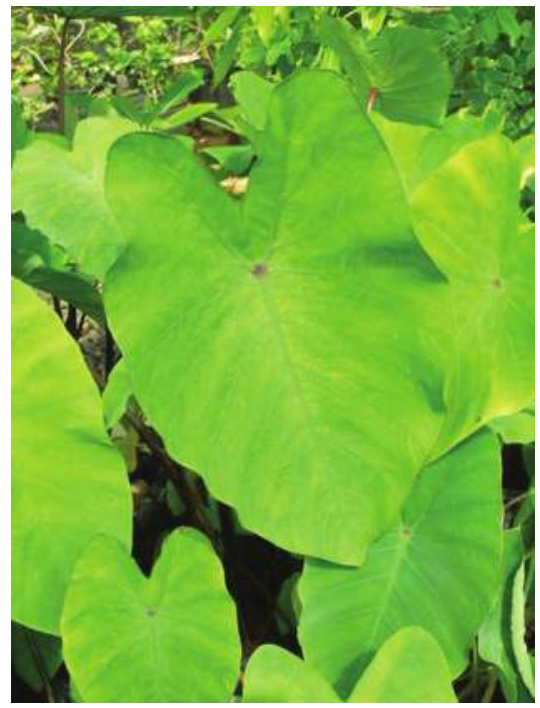

Gambar 10

Permukaan daun

http://kimmyaulia.blogspot.com/2014/06/ morfologi-tumbuhan-praktikum-1-daun.html (Diakses pada 26/05/2015-20:00)

d. Gundul (Glaber)

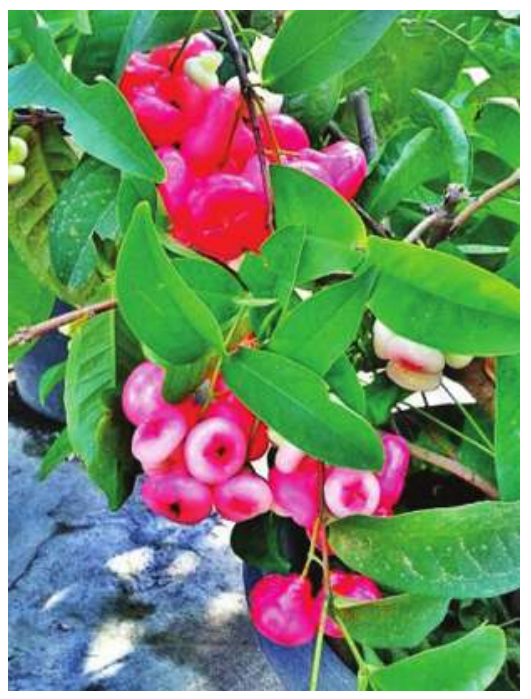

Gambar 11

Permukaan daun

http://belajar-di-rumah.blogspot.com/2015/03/ permukaan-daun.html

(Diakses pada 26/05/2015-20:00) 


\section{e. Berkerut (Rugosus)}

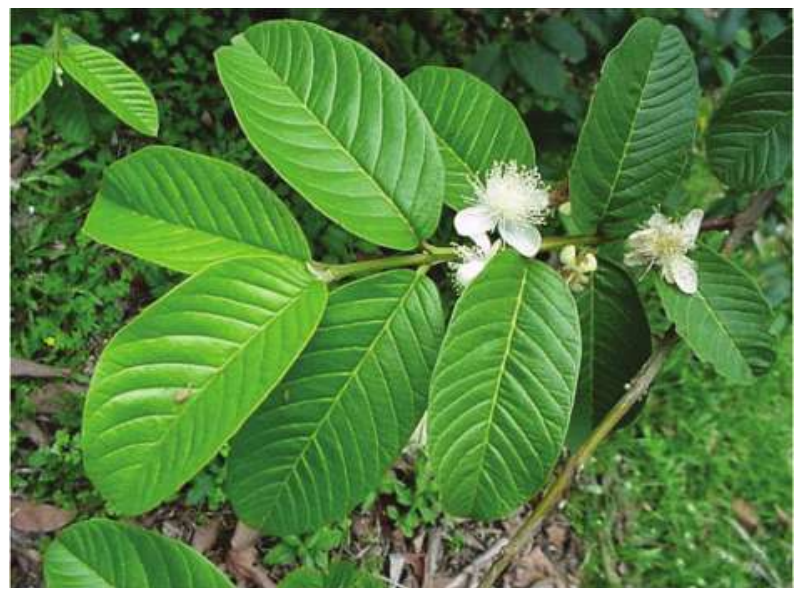

Gambar 12

Permukaan daun

http://belajar-di-rumah.blogspot.com/2015/03/ permukaan-daun.html

(Diakses pada 26/05/2015-20:00)

Berdasarkan susunan tulang daun:

a. Tulang daun menyirip

Tulang daun menyirip berbentuk seperti susunan sirip ikan.

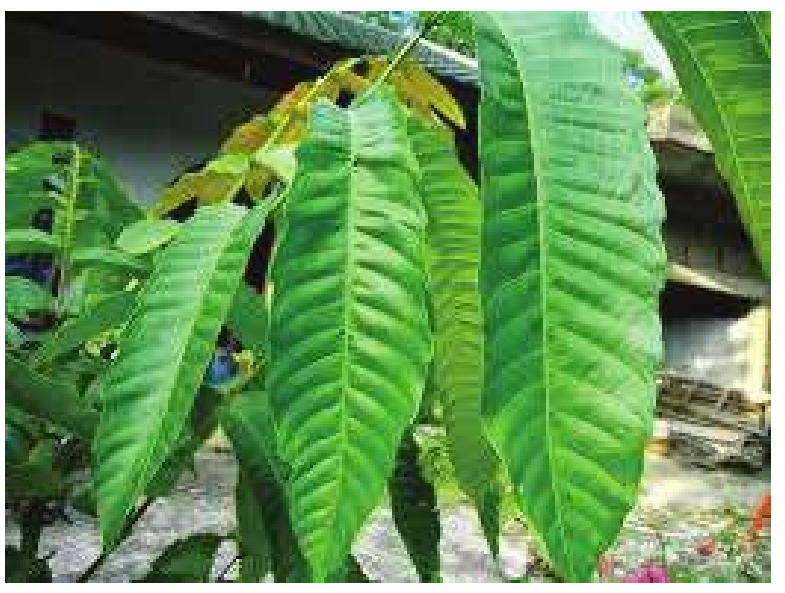

Gambar 13

Tulang daun

http://www.cpuik.com/2012/09/macam-macamsusunan-tulang-daun.html

(Diakses pada 26/05/2015-20:00)

b. Tulang daun melengkung

Bentuk tulang daun melengkung seperti garis-garis lengkung menjadi satu pada ujung daun.

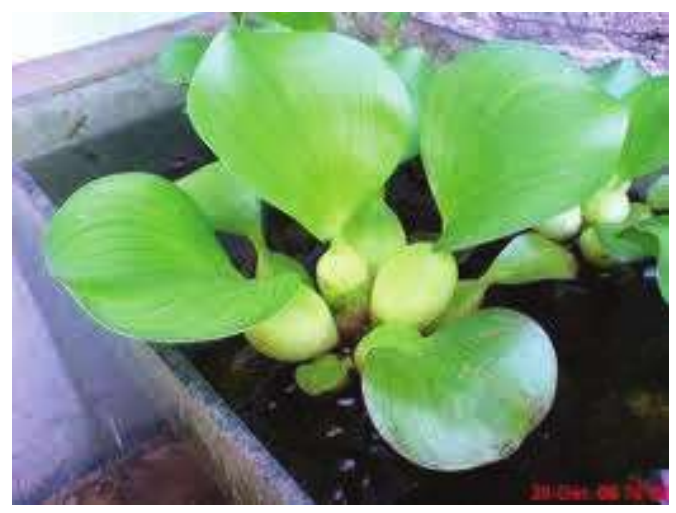

Gambar 14

Tulang daun

http://www.cpuik.com/2012/09/macam-macamsusunan-tulang-daun.html

(Diakses pada 26/05/2015-20:00)

Teknik cetak chlorophyll print membutuhkan sinar matahari atau sinar UV untuk perwujudan image, dalam teknik ini proses fotosintesis merupakan langkah perwujudan visual. Daun segar sangat baik untuk media cetak. Bagian atas daun yang bersih kemudian dilapisi dengan film positif dan dijepit diantara mika akrilik dan multiplex. Lamanya waktu exposure tergantung dari jenis daun yang digunakan, untuk daun alas (Colocasa esculenta), daun jeruk Bali (Citrus maxima) membutuhkan waktu sektar 3-4 jam saat cuaca cerah. Cuaca mendung juga menjadi hambatan teknik chlorophyll print, meski gambar dapat dicetak di atas daun setidaknya butuh waktu minimal 12 jam untuk penyinaran. Terlalu cepat atau terlalu lama men-exposure daun di bawah sinar matahari juga bisa menyebabkan under exposure dan over exposure. Pengamatan daun yang sedang disinari menjadi salah satu cara untuk mengetahui proses exposure agar gambar dapat tertransfer dengan hasil yang baik.

\section{Proses Perwujudan}

Melakukan proses cetak di atas daun memerlukan waktu penyinaran dengan cahaya UV (lebih baik langsung sinar matahari) karena 
dalam proses memanfaatkan proses fotosintesis dengan sel chlorophyll yang dimiliki daun. Penyinaran ini membutuhkan waktu +/-180 menit, bisa juga sampai berhari-hari bahkan mingguan.

\section{Persiapan alat}

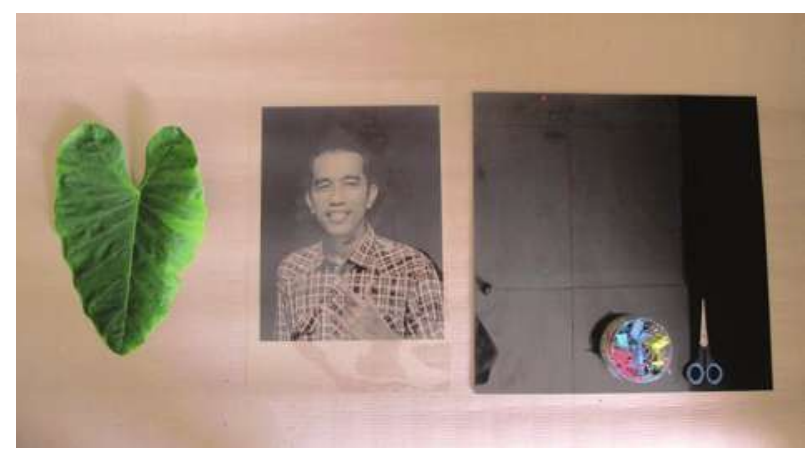

Gambar 15

Peralatan yang dibutuhkan seperti contoh gambar 15 adalah (1) daun, (2) film positif, (3) penjepit, (4) alat potong, (5) alas daun multiplex atau kaca (harus solid, tidak lentur), dan (6) akrilik transparan sekuran daun yang akan dicetak.

\section{Pemilihan daun}

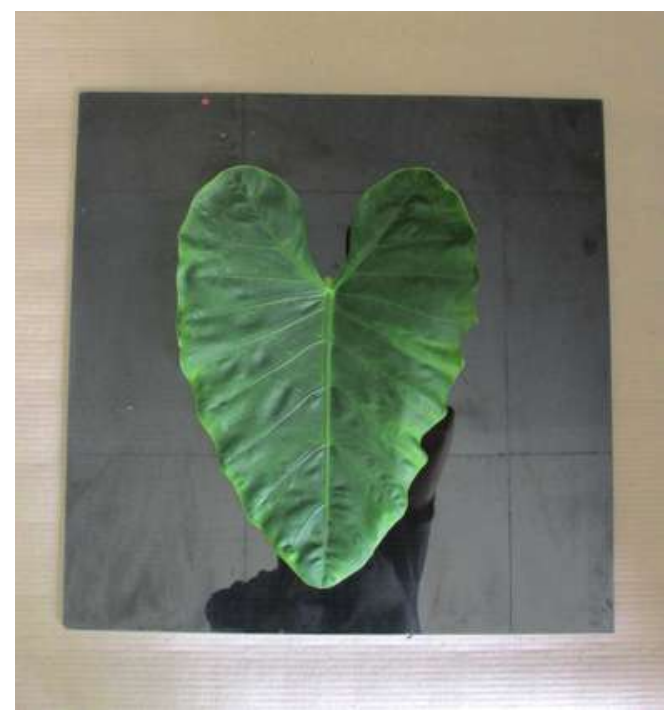

\section{Gambar 16}

Letakkan daun di atas alas yang solid, kemudian letakkan film di atas daun seperti gambar 18 .

\section{Posisi film positif}

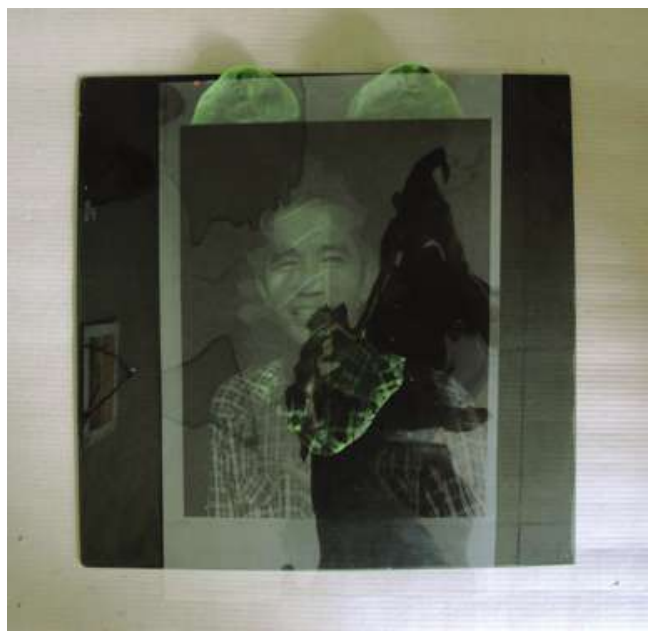

Gambar 17

Film positif diletakkan di atas daun

Posisi layer penahan film

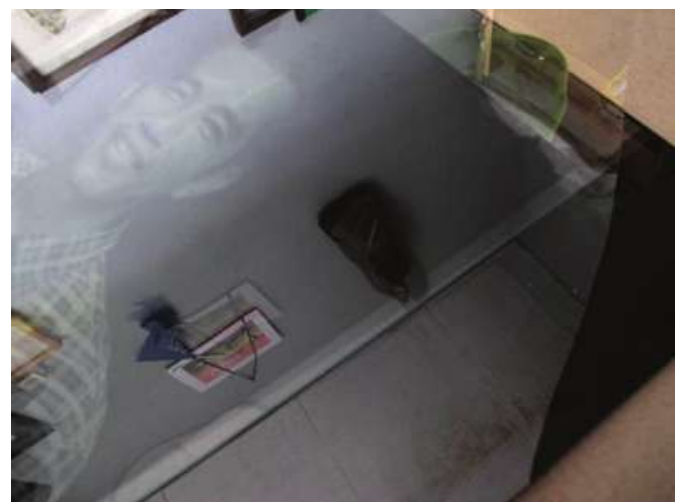

\section{Gambar 18}

Setelah film dikomposisikan di atas daun, letak kaca bening di atas film. Kemudian gunakan penjepit untuk mengeratkan kaca bening dengan alas daun.

\section{Exposure}

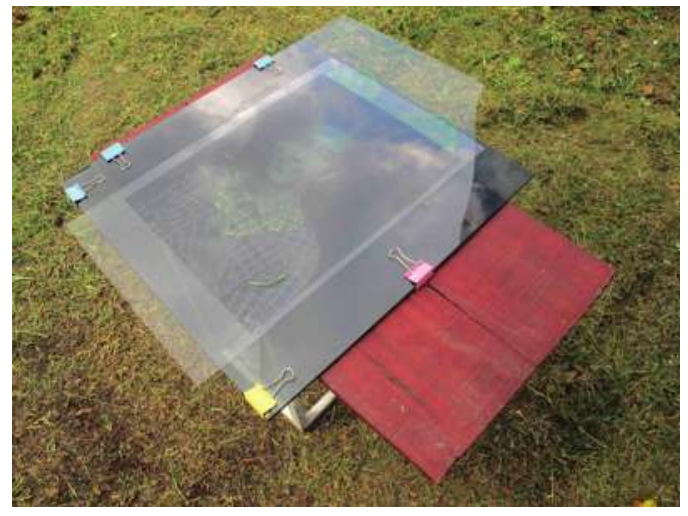

Gambar 19

Lalu jemur daun di bawah sinar matahari, lama penyinaran tergantung dengan kondisi cuaca. 
Hasil dari penyinaran

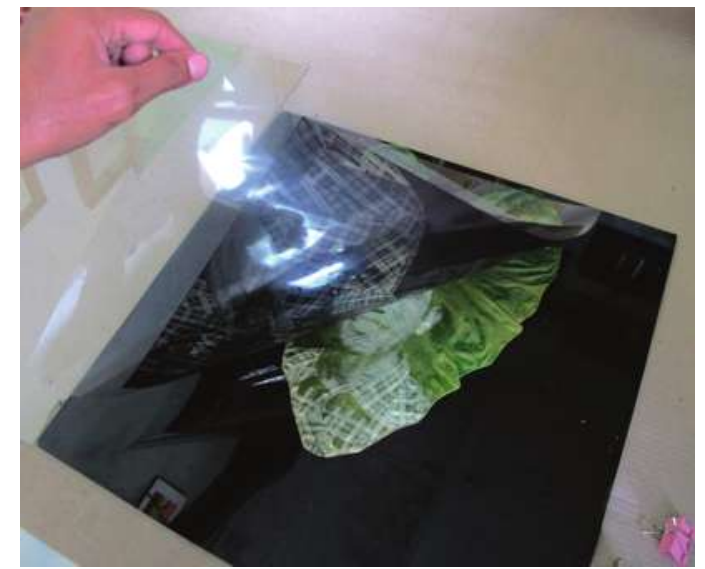

Gambar 20

Setelah 240 menit di bawah penyinaran matahari dan gangguan awan mendung. Lepaskan kaca bening dengan film dari daun (lepaskan film secara perlahan untuk menghindari kerusakan atau luka pada daun).

\section{Karya chlorophyll print}

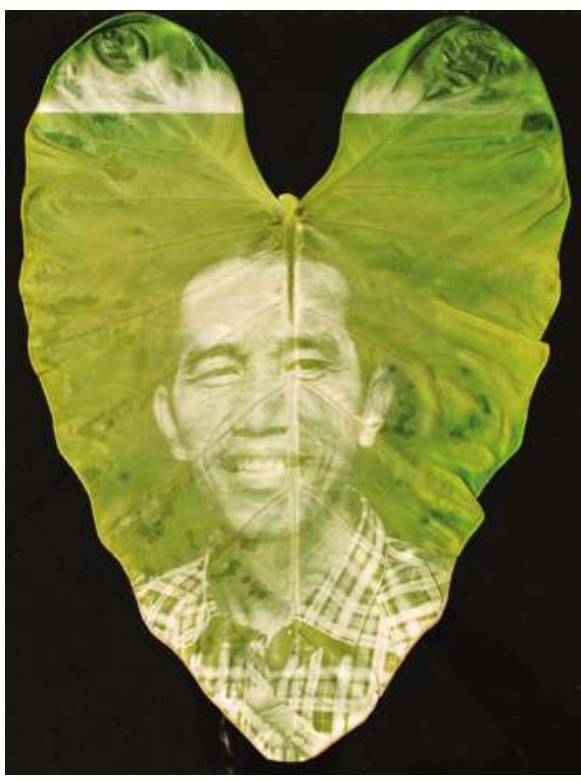

Gambar 21

Inilah hasil yang didapat dari penyinaran matahari dengan memanfaatkan sel klorofil dengan proses fotosintesis.

\section{PEMBAHASAN}

Sejak ditemukannya fotografi, manusia semakin mudah menghasilkan imaji yang sebelumnya hanya dapat dilakukan melalui penggambaran dengan tangan. Kemudahan yang didapat pada fotografi akhirnya dimanfaatkan untuk berbagai kebutuhan visual. Oleh karena itu, sejak adanya temuan-temuan lain dalam fotografi berkembang pesat, seperti teknologi dan pemikiran-pemikiran fotografi, fotografi menjadi medium yang sangat potensial bahkan radikal dibanding dengan kegiatan visual lain, karena kemampuannya untuk menghadirkan sebuah realitas dengan nilai presisi tinggi. Secara ideational, wacana fotografi berkembang dari kesadaran manusia sebagai mahluk yang berbudi/berakal yang memiliki kemampuan lebih untuk dapat merekayasa alam lingkungan kehidupannya. Hal ini merupakan alasan yang kuat untuk memungkinkan tetap 'survive' dan menciptakan berbagai 'karya kehidupan' sebagai 'tanda' eksistensinya di dunia ini (Soedjono 2006:8).

Dalam fotografi cahaya merupakan pendukung utama pembentukan image, tanpa adanya cahaya maka sebuah foto tidak akan dapat diwujudkan. Secara teknis proses mencetak gambar dalam fotografi pada era analog membutuhkan cahaya untuk mewujudkan image menuju media cetak konvensional berupa kertas peka cahaya. Karya chlorophyll print hampir mirip dengan karya fotografi konvensional pada era analog. Kelebihan mencetak dengan chlorophyll print tidak membutuhkan kamar gelap karena yang dimanfaatkan dari media daun untuk mewujudkan image adalah zat klorofil proses fotosintesisnya.

Proses komputerisasi dilakukan setelah pemotretan untuk memproduksi film positif. Tahap ini bisa ditangani oleh pihak lain seperti percetakan yang biasa menangani pembuatan film untuk sablon. Film positifyang dipersiapkan untuk dicetak di atas media daun memiliki rasio $1: 1$, artinya film yang akan dicetak memiliki ukuran yang sama besar dengan hasil image yang akan tertransfer ke atas media daun. 
Cita rasa keindahan karya chlorophyll print merupakan aktivitas artistik. Material daun seperti warna monochrome, tekstur, bentuk, komposisi, dan pola-pola menjadi susunan persepsi yang dibalut oleh perasaan atau emosi maka dapat diekspresikan dalam wujud pemikiran ideational, hingga technical dalam bentuk karya.

\section{SIMPULAN}

Daun sebagai media cetak memiliki kelebihan yang ramah terhadap lingkungan. Daun juga memberikan banyak manfaat bagi manusia, contohnya sebagai sumber oksigen, pengobatan alternatif, pembungkus makanan, sebagai peneduh, seni kerajinan, hiasan, hampir semua dapat memberikan rasa keindahan, nyaman, dan kesenangan.

Penciptaan seni fotografi dengan teknik cetak chlorophyll print ini merupakan pengalaman estetis penulis dan beberapa seniman lain, dengan harapan bisa dibagikan untuk bereksplorasi, berkreasi, bereksperimen, dan berekspresi yang memanfaatkan teknologi digital juga proses cetak analog. Tulisan ini juga bertujuan sebagai pemahaman bagaimana fotografi tidak dapat lepas dari cahaya, bagaimana gambar itu dapat tercipta, terutama bagai pencinta fotografi yang mampu memproses gambarnya sendiri, dengan memanfaatkan teknologi fotografi yang tengah berkembang pesat. Semoga teknik cetak chlorophyll print dapat memperkaya kosa visual fotografi di tanah air dan menjadi alternatif untuk mewujudkan sebuah karya fotografi.

\section{KEPUSTAKAAN}

Azahari, Mustaffa Halabi. 2011. Photography Its Significance Strands and Values in Education. Shah Alam: University Publication Center.

Hartoko, Dick. 1984. Manusia dan Seni. Yogyakarta: Kanisius.

Lakitan, Benyamin. 2012. Dasar-Dasar Fisiologi Tumbuhan. Jakarta: Rajawali Pers.

Longman. 2001. Handy Learner's Dictionary of American English. England: Pearson Education Limited.

Muzayyinah. 2008. Terminologi Tumbuhan. Surakarta: Universitas Sebelas Maret.

Soedjono, Soeprapto. 2006. Pot-Pourri Fotografi . Jakarta: Universitas Trisakti.

Worobiec, Tony \& Ray Spence. 2003. Photo Art. New York: Amphoto Books.

\section{Pustaka Laman}

www.artikata.com. Bentuk Daun (26/05/201520:00).

http://ghinaghufrona.blogspot.com/2011/08/ morfologi-daun.html.Binh Danh (13 Februari 2014).

http://wmuphoto.wordpress.com/2010/01/20/ binh-danh/.Heather Ackroyd \& Dan Horvey (12 Februari 2014).

http://www.viewingspace.com/genetics_ culture/pages_genetics_culture/gc w02/gc_w02_ackroyd_harvey.htm. Kelas Biologku - Proses fotosintesis (22 Mei 2015),

http://kelasbiologiku.blogspot.com/2013/03/ reaksi-dan-proses-fotosintesis pada. html. Permukaan Daun (Diakses pada 26 Mei 2015).

http://mortumklasifikasitumbuhan.blogspot. com/2013/10/bangun-daun_7436.html. Permukaan Daun (Diakses pada 26 Mei 2015).

http://andiibm.blogspot.com/2014/04/ jeruk-nipis-citrusaurantifolia.html. 
Permukaan Daun (Diakses pada $26 \mathrm{Mei}$ 2015).

http://kimmyaulia.blogspot.com/2014/06/

morfologi-tumbuhan-praktikum-1daun.html. Permukaan Daun (Diakses pada 26 Mei 2015).

http://belajar-di-rumah.blogspot.com/2015/03/ permukaan-daun.html.Tulang daun

(Diakses pada 26 Mei 2015).

http://www.cpuik.com/2012/09/macammacam-susunan-tulang-daun.html. Wikipedia (13 April 214).

http://id.wikipedia.org/wiki/Fotosintesis. 